\title{
SERVIÇOS DE PAISAGISMO NO ESTADO DE SÃO PAULO
}

\author{
Juliana Cristina Augusto Shams ${ }^{1}$; Ana Maria Liner Pereira Lima²; Cibele Zanforlin ${ }^{3}$
}

(recebido em 05.09.2010 e aceito para publicação em 15.12.2010)

\section{RESUMO}

Para traduzir a realidade da prestação de serviços em paisagismo, o presente trabalho compõe-se de entrevistas, com empresas deste setor, nas cinco regiões metropolitanas e administrativas, do Estado de São Paulo, que representam a geração de $85,2 \%$ do PIB paulista. Para fins de amostragem, considerou-se as cidades-sede dessas regiões: São Paulo, Campinas, São José dos Campos, Sorocaba e Santos, nas quais foram identificadas as prestadoras desses serviços, pelo meio de divulgação da empresa Publicar, disponível no Guia Mais, em sua versão on-line. Após este levantamento, $20 \%$ das empresas foram analisadas, totalizando 50 entrevistas. Os resultados obtidos comprovaram que os trabalhos de paisagismo são associados à jardinagem, em suas mais diversas formas; identificaram a heterogeneidade de formação dos profissionais neste setor, sendo arquitetos (25\%) e agrônomos $(23,33 \%)$ os mais destacados nesta atividade, porém, a atuação desses profissionais segue superada por aqueles sem habilitação para a prestação deste serviço (51,57\%). Isso confirma que o mercado de paisagismo não tem tido muitas regras e orientações, ou não as tem cumprido de forma legal. $E$ isso também demonstra que seus empreendedores (96\%) têm projetado prosperidade ao setor; entretanto, evidenciam que os recém-formados, que se oferecem a este mercado, estão despreparados para atendê-lo de forma satisfatória (88\%).

Palavras-chave: mercado de paisagismo, empresas de paisagismo, habilitação profissional, jardinagem.

1 Engenheira Agrônoma, Mestre em Ciências pelo Programa de Pós-graduação em Fitotecnia - ESALQ/USP. Piracicaba, SP. E-mail: ju.shams@gmail.com

${ }^{2}$ Engenheira Agrônoma, Profạ. Dra . do Departamento de Produção Vegetal - ESALQ/USP. Piracicaba, SP. E-mail: amlplima@esalq.usp.br

${ }^{3}$ Arquiteta, Especialista em Educação Ambiental pelo CRHEA - EESC/USP. São Carlos, SP. E-mail: czanforlim@hotmail.com 


\section{LANDSCAPING SERVICES IN THE STATE OF SAO PAULO}

\section{ABSTRACT}

To obtain data that reflects the reality of services in landscaping, this work consists of interviews with providers of landscaping services in the five metropolitan and administrative regions of the State of Sao Paulo, which represent $85.2 \%$ of its GDP. For sampling purposes, we considered the host cities of these regions the following ones: Sao Paulo, Campinas, Sao Jose dos Campos, Sorocaba, and Santos, in which the identification of the universe of companies was done, based on the disclosure service provided by the company Publicar, available in the Guia Mais, in its online version. From this survey $20 \%$ of the companies found were analyzed, summing a total of 50 interviews. The results obtained support the view that the landscaping works are associated to gardening, in its various forms; another finding was the heterogeneity of the areas of formation of professionals in this field, being architects (25\%) and agronomists (23.33\%) those who stand out in this activity, however, the performance of these professionals is surpassed by those without accreditation for this activity (51.57\%). This fact confirms the idea that the landscaping market has not had many rules and guidelines or at least has not established legal norms. It demonstrates that, despite all the challenges, entrepreneurs (96\%) have projected prosperity in the field; however, it is perceived that newly graduated students who offer services for developing this kind of work are unprepared to perform them satisfactorily (88\%).

Keywords: landscaping market, landscaping companies, professional accreditation, gardening. 


\section{INTRODUÇÃO}

Repensar as associações feitas ao paisagismo, os tipos de serviços oferecidos, as perspectivas do mercado atual e a atuação profissional, a partir daqueles que oferecem esse serviço, é uma tentativa de propiciar maior aproximação, sintonia e profissionalidade a este emergente setor brasileiro.

De acordo com Cesar (2003), a classificação do paisagismo contemporâneo toma como base algumas vertentes que concentram visões e práticas profissionais diversas. $A$ primeira vertente concentra o paisagismo com ênfase na arquitetura da paisagem, cujo enfoque vê todos os espaços como arquitetura, sendo a vegetação também elemento de composição. A segunda vertente é o paisagismo com ênfase na percepção que explora aspectos sensoriais e psicológicos. A terceira vertente concentra o paisagismo ambiental, englobando várias práticas mais voltadas à preservação, que servem de pré-requisito ao desenvolvimento sustentável; valorizando os aspectos ecossistêmicos.

Neste contexto, percebe-se a paisagem com a utilização da vegetação, o que, segundo Drumond (2005) não é obrigatoriedade para concretização de um projeto paisagístico; porém, no Brasil, um país onde há abundância de uma vegetação exuberante, os projetos, na maioria das vezes, estão diretamente associados ao uso de espécies vegetais, visto que estas desempenham várias funções que podem melhorar significativamente os locais tratados. Conforme Vieira (2007), a arquitetura paisagística contemporânea está calcada sobre valores relacionados à proteção e à manutenção do meio ambiente.

Seguindo pesquisa realizada por Zuin (2002), adquiri-se uma boa ilustração para a compreensão geral do termo paisagismo no Brasil, uma vez que o autor identifica, a partir de análises em web sites brasileiros, que tratam sobre paisagismo, as abordagens referidas pelos mesmos, em seus conteúdos; demonstrando que a associação do paisagismo com a jardinagem é predominante, sendo destaque em $69 \%$ dos web sites analisados.

$\mathrm{Na}$ visão de Medeiros (2008), o paisagismo no Brasil passa a incorporar as preocupações ecológicas e por isso também, é mais demandado a fazer parte de construir e pensar as cidades. Seguindo Spirn (1995), a cidade não é nem totalmente natural, nem totalmente artificial, e a desconsideração dos projetos naturais é, e sempre será, tão custosa quanto perigosa. Desta forma, o paisagismo tem papel conciliador proporcionando melhorias sociais e ambientais às cidades, atendendo à emergente necessidade que ora se aponta.

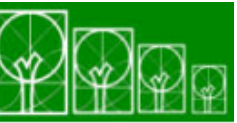

$\mathbf{S} \cdot \mathbf{B} \cdot \mathbf{A} \cdot \mathbf{U}$ Soc. Bras. de Arborização Urbana

REVSBAU, Piracicaba - SP, v.5, n.4, p.57-80, 2010 
O atendimento real a esta necessidade crescente pode ser, em muitos casos, questionada, já que a paisagem, como salienta Arendt (2005), adquire uma imagem que vai além de sua materialidade, e que fica totalmente imbricada de valor monetário, financeiro, valor simbólico e real, adquirindo caráter atrelado a um motor hegemônico - o capitalismo.

Nota-se envolvimento do mercado imobiliário na construção ou manutenção das paisagens, nos centros urbanos e, segundo Harvey (2001), especuladores, procurando maximizar seus ganhos, a partir do aumento da renda da terra, estão atualmente reformando e reformatando ambientes metropolitanos, utilizando de recursos naturais. De acordo com Wendel (2006), no período histórico atual, em várias cidades do Brasil e do mundo, qualquer objeto associado a uma idéia de natureza torna-se sinônimo de qualidade de vida e transforma-se em valor econômico.

O perigo eminente, da relação do paisagismo aos interesses econômicos, é a realização desta atividade sem os adequados conhecimentos necessários à sua realização, e a exclusão da ética, em seu processo de criação, em seus 3 sub-temas básicos: ética ambiental, ética profissional e ética social, como destacado por Zuin (2005).

De acordo com Zuin (2002), a popularidade dos paisagistas, deu a esta atividade um estatuto de carreira desejável e próspera, e como resultado, os cursos de paisagismo tornaram-se uma indústria lucrativa. Segundo pesquisa deste autor, os cursos livres de paisagismo contam com público que inclui, juntamente com profissionais já atuantes, alunos de nível primário, médio, estudantes e formados em cursos superiores correlacionados ao paisagismo, que buscam complementação de sua formação. Muitos são provenientes de áreas mais distantes e buscam mudança de rumo profissional; tal situação reproduz a formação de paisagistas no Brasil, seguindo a lenda de Burle Marx, como auto-didata.

Em discussão sobre o mercado de trabalho de paisagismo no Brasil, Pettan e Gonçalves (1998) levantaram a inexistência de um banco de dados de profissionais e chamaram a atenção para a dificuldade de coleta de informações em seu contexto, o que tem sido um dos desafios ao desenvolvimento do paisagismo brasileiro. $\mathrm{Na}$ visão de Barbosa (1989), a prática do paisagismo em mãos inábeis acaba por deturpar suas finalidades principais, muitas vezes transmutando-o em mera mercantilização do verde.

Sendo assim, esta pesquisa objetiva estabelecer a visão que as prestadoras de serviços de paisagismo possuem quanto ao mercado em que atuam, identificando seus profissionais e suas expectativas quanto à formação acadêmica, para atender a este setor. 


\section{MATERIAIS E MÉTODOS}

\section{Área de estudo}

A demanda por serviços relacionados ao paisagismo tem sido relacionada a interesses econômicos, atrelada ao mercado imobiliário e imbricada de valor monetário, e, baseando-se nisto, considerou-se, para análise e representação, o Estado de São Paulo, o qual localiza-se na região sudeste do Brasil, e apresenta-se como o Estado mais rico, com a segunda maior renda per capita da Federação. Possui uma economia diversificada, cuja base, de acordo com o Instituto Brasileiro de Geografia e Estatística (IBGE, 2007), responde por $33,9 \%$ do Produto Interno Bruto (PIB) brasileiro.

Uma vez associado os serviços de paisagismo com as condições econômicas do Estado, considerou-se suas divisões em regiões metropolitanas e administrativas, possibilitando visão e análise concisa, quanto à contribuição econômica que cada uma desempenha em seu contexto. Representando as regiões mencionadas, segue a Figura 1.

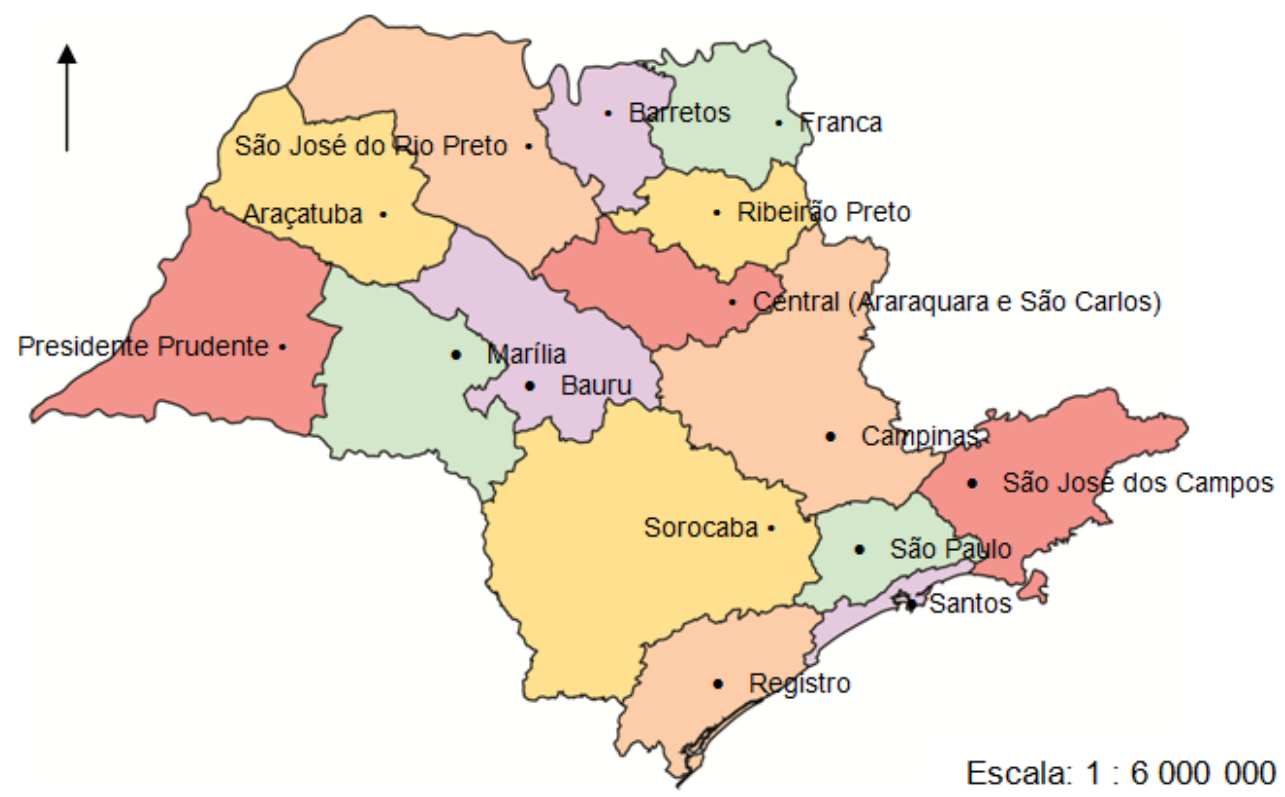

Fonte: Adaptado de IGC (2009).

FIGURA 1 - Regiões administrativas e metropolitanas do Estado de São Paulo, e suas respectivas cidades-sede.

FIGURE 1 - Administrative and metropolitan regions of Sao Paulo and their respective host cities. 
Para determinar a contribuição, de cada uma das regiões, utilizou-se de informações do Sistema Estadual de Análise de Dados (SEADE, 2008), o qual afirma que a Região Metropolitana de São Paulo responde por mais da metade do PIB total do Estado (56,1\%). Entre as regiões administrativas, a maior é a de Campinas (15,4\%), seguida pelas de São José dos Campos (5,2\%), Sorocaba $(4,7 \%)$ e Santos (3,8\%). Em conjunto, estas cinco regiões identificadas respondem pela geração de $85,2 \%$ do PIB paulista. Desta forma, considera-se que estas regiões representam a demanda mais significativa quanto à solicitação de serviços de paisagismo, no Estado.

Tendo como base as cinco regiões selecionadas, optou-se pela investigação e amostragem nas cidades-sede de cada uma delas: São Paulo, Campinas, São José dos Campos, Sorocaba e Santos (Figura 2).

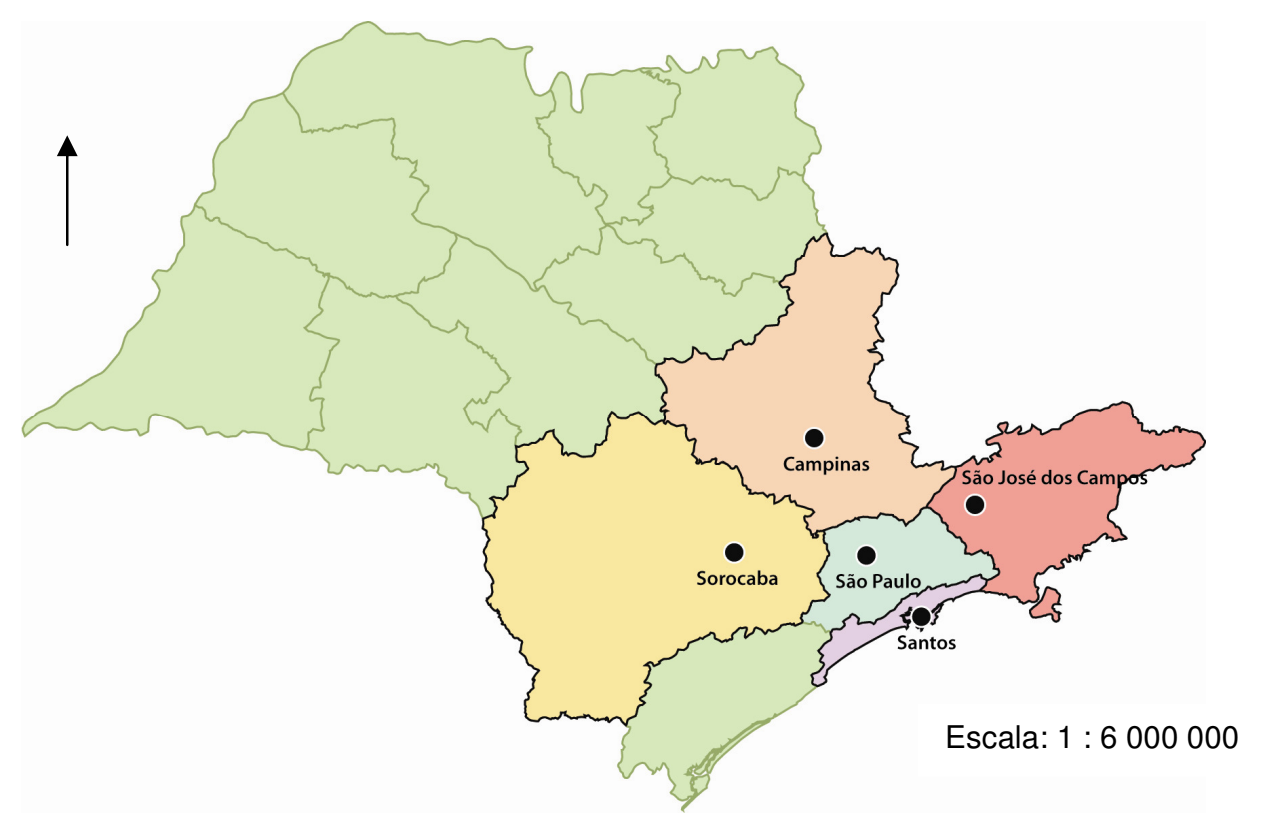

Fonte:Adaptado de IGC, 2009.

FIGURA 2 - Localização das cidades-sede amostradas, dentro da região à qual pertencem. FIGURE 2 - Location of the host cities sampled within the region to which they belong.

\section{População e amostra}

Visando identificar as empresas que prestam serviços e oferecem produtos relacionados ao paisagismo, optou-se por seguir duas estratégias, sendo a primeira delas a identificação a partir de registros, junto às prefeituras e órgãos administrativos municipais; 
como segunda opção, considerou-se determinar as empresas, aproveitando de suas estratégias de divulgação, onde oferecem seus serviços ao público em geral.

Com o propósito de realizar o levantamento, de acordo com a primeira opção, seriam contatados os órgãos municipais para averiguação de seus registros, bem como das possibilidades de torná-los disponíveis a esta pesquisa. Na segunda opção apresentada, a mais adequada fonte para determinação das empresas, seria considerar a listagem obtida junto ao serviço de divulgação, prestado pela empresa Publicar, que disponibiliza guias e listas de serviços à população.

De acordo com Gasparin (2006), esta empresa opera no Brasil, sendo líder no segmento de listas e guias, em todas as regiões do país. Já possuía as marcas Editel, Encontre e Compre, Guia Aqui, Listel e Lista On-line e, em 2007, incorporou a marca líder do segmento em São Paulo e no Rio de Janeiro, o Guia Mais, com as versões impressa, disk e on-line.

Para análise direcionada aos serviços de paisagismo seria utilizado o serviço do Guia Mais, em seu formato on-line, disponível no site www.guiamais.com, viabilizando a identificação das empresas, a partir da busca por "paisagismo".

Realizado o levantamento das empresas, considera-se, para fins de amostragem, que $20 \%$ delas efetivamente deveriam oferecer dados a esta pesquisa, sendo este percentual distribuído de forma proporcional, em função do número de prestadoras de serviço listadas em cada uma das cidades analisadas.

\section{Forma de coleta dos dados}

Com a listagem das empresas a serem amostradas, inicia-se o estabelecimento de contato com as mesmas, via telefone, para identificar aquelas cujos profissionais ou responsáveis estivessem dispostos a fornecer informações. A coleta das informações concretiza-se a partir de entrevista individual, via telefone, de forma semi-estruturada, com questões de múltipla escolha, devido às suas vantagens para o processamento dos dados recolhidos, porém, permitindo a anotação de possíveis comentários adicionais.

Um questionário próprio foi elaborado para a coleta dos dados e, seguindo Günther (2003), a elaboração do questionário partiu da reflexão quanto ao objetivo da pesquisa em termos dos conceitos a serem pesquisados e da população-alvo. Utilizou-se, como base de desenvolvimento as experiências dos pesquisadores, o contato com a população a ser amostrada e a visão literária do assunto pretendido.

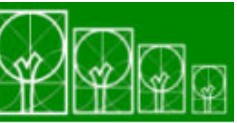

$\mathbf{S} \cdot \mathbf{B} \cdot \mathbf{A} \cdot \mathbf{U}$ Soc. Bras. de Arborização Urbana

REVSBAU, Piracicaba - SP, v.5, n.4, p.57-80, 2010 
O questionário utilizado para entrevista é composto de três áreas de investigação: caracterização das empresas entrevistadas (Figura 3); aspectos relativos à visão quanto ao mercado de paisagismo no Estado (Figura 4); e aspectos da formação dos profissionais para atuação em paisagismo. (Figura 5).

1. Há quanto tempo a empresa oferece serviços de paisagismo?

2. Quais são os serviços, relacionados ao paisagismo, oferecidos pela empresa?

3. Qual é a formação do(s) profissional(is) que oferece $(\mathrm{m})$ esses serviços?

4. Qual é a situação do mercado de paisagismo para a empresa neste momento?

( ) Ótima ( ) Boa ( ) Regular ( ) Ruim ( ) Péssima

FIGURA 3 - Questões elaboradas para caracterização das empresas entrevistadas.

FIGURE 3 - Questions designed to characterize the companies interviewed.

As questões apresentadas na Figura 3 foram as únicas que não ofereceram possibilidade de comentários adicionais.

5. Acredita que os trabalhos com paisagismo são promissores no Estado?

$$
\text { ( ) } \operatorname{Sim} \text { ( ) Não }
$$

6. Acredita ser importante a participação de mais de um profissional na construção de paisagens? ( ) Sim ( ) Não

Quais deveriam ser os profissionais envolvidos?

( ) Arquiteto |（）Biólogo |（）Engenheiro Agrônomo |（）Engenheiro Florestal |

( ) Geógrafo | ( ) Outros.

FIGURA 4 - Questões relativas à visão quanto aos serviços de paisagismo no estado.

FIGURE 4 - Questions related to the view of landscaping services in the state.

Vale destacar que a questão 6 , buscou a visão que as empresas de paisagismo têm quanto aos trabalhos de multiprofissionais na construção das paisagens expondo alternativas que determinam as origens acadêmicas mais frequentes dos paisagistas brasileiros, como determinado por Zuin (2002). 
7. Sente que os recém-formados têm interesse por trabalhos de paisagismo?

( ) $\operatorname{Sim}($ ) Não

8. Sente que os recém-formados foram devidamente capacitados pelas instituições de ensino superior, para o oferecimento de serviços relacionados ao paisagismo?

( ) $\operatorname{Sim}($ ) Não

FIGURA 5 - Questões quanto aos aspectos da formação dos profissionais para atuação em paisagismo.

FIGURE 5 - Questions regarding the aspects of training professionals to work in landscaping.

\section{RESULTADOS E DISCUSSÃO}

Buscou-se realizar a identificação da população a ser amostrada, a partir de registros, junto às prefeituras e órgãos administrativos municipais; entretanto, esta realização não foi possível, em função de registros desatualizados, e pelo não registro das empresas como sendo prestadoras de serviços relacionados ao paisagismo; muitas delas, mesmo oferecendo este trabalho, estão registradas com outras descrições, impossibilitando a visão real do mercado amostrado.

Frente a esta realidade, a pesquisa seguiu com sua segunda opção, que foi utilizar os serviços da empresa Publicar, procurando por "paisagismo" na opção de busca do Guia Mais, em seu formato on-line, nas cidades selecionadas. A partir desta busca, identificou-se 230 empresas que oferecem serviços de paisagismo (Tabela 1).

TABELA 1 - Número de empresas identificadas a partir de busca por "Paisagismo", realizada no site www.guiamais.com. Acesso em: 19 abr. 2009.

TABLE 1 - Number of companies identified from the query "Landscaping", performed at the site www.guiamais.com. Accessed: April 19, 2009.

\begin{tabular}{cc}
\hline Cidades paulistas & $\mathbf{N}^{\circ}$ de empresas identificadas \\
\hline São Paulo & 136 \\
Campinas & 52 \\
São José dos Campos & 20 \\
Santos & 14 \\
Sorocaba & 08 \\
\hline Total & $\mathbf{2 3 0}$ \\
\hline
\end{tabular}


Para determinação do número amostrado de empresas que, efetivamente, poderiam representar a região de maior influência econômica no Estado, considerou-se, um mínimo de $20 \%$ do número total de empresas encontradas em cada uma delas (Tabela 2).

TABELA 2 - Número de empresas amostradas em cada uma das cidades selecionadas.

TABLE 2 - Number of companies sampled in each of the cities selected.

\begin{tabular}{cc}
\hline Cidades-sede & $\mathbf{N}^{\circ}$ de empresas amostradas \\
\hline São Paulo & 28 \\
Campinas & 11 \\
São José dos Campos & 4 \\
Santos & 4 \\
Sorocaba & 3 \\
\hline Total & $\mathbf{5 0}$
\end{tabular}

Em função do percentual amostrado, calculou-se que, para análise dos resultados das questões apresentadas, o erro amostral é de 15,62\%, com 90\% de probabilidade.

1. Há quanto tempo a empresa oferece serviços de paisagismo?

As respostas desta questão foram agrupadas em intervalos de anos (Tabela 3).

TABELA 3 - Tempo de atuação das empresas de paisagismo amostradas.

TABLE 3 -Time on the market of the landscaping companies sampled.

\begin{tabular}{ccc}
\hline $\begin{array}{c}\text { Tempo de atuação das empresas } \\
\text { (em anos) }\end{array}$ & $\begin{array}{c}\text { Frequência } \\
\text { (Nº de empresas) }\end{array}$ & Percentual (\%) \\
\hline 0 a 5 & 11 & 22 \\
6 a 10 & 10 & 20 \\
11 a 15 & 15 & 30 \\
16 a 20 & 4 & 08 \\
Acima de 20 & 10 & 20 \\
\hline Total & $\mathbf{5 0}$ & $\mathbf{1 0 0}$
\end{tabular}

Os resultados apresentados demonstram que, no mercado de paisagismo, podem ser encontradas empresas que são iniciantes no ramo, aquelas com longa data no mercado e, ainda, as intermediárias no oferecimento desses serviços. Tal fato acaba por constatar que a atuação neste mercado não é recente, mas vem recebendo investimentos, para abertura de novos empreendimentos, ao longo dos últimos anos.

Destaca-se a atuação de prestadoras de serviços de paisagismo há mais de 10 anos no mercado, cujo percentual é de $58 \%$. A partir de uma análise geral, constata-se que as 
empresas, que oferecem serviços de paisagismo, apresentam um tempo médio de atuação de 13,27 anos.

2. Quais são os serviços, relacionados ao paisagismo, oferecidos pela empresa?

Os resultados desta questão constatam que os serviços oferecidos como paisagismo estão diretamente relacionados a jardins e utilização de plantas ornamentais (Tabela 4).

TABELA 4 - Serviços relacionados ao paisagismo oferecidos pelas empresas amostradas.

TABLE 4 - Landscaping related services offered by the companies sampled.

\begin{tabular}{ccc}
\hline Serviços oferecidos & $\begin{array}{c}\text { Frequência } \\
\text { (N }{ }^{\circ} \text { de empresas) }\end{array}$ & Percentual (\%) \\
\hline Reforma de jardins & 50 & 100 \\
Implantação de jardins & 48 & 96 \\
Manutenção de jardins & 48 & 96 \\
Elaboração de projetos paisagísticos & 35 & 70 \\
Venda de plantas ornamentais & 32 & 64 \\
Venda de mudas arbóreas & 32 & 64 \\
Venda de flores de corte & 21 & 42 \\
\hline
\end{tabular}

A Tabela 1.4 oferece uma boa ilustração daquilo que é chamado de serviço de paisagismo, comprovando que os mesmos são associados à jardinagem; como verificado por Zuin (2002), quando da pesquisa em web sites brasileiros sobre paisagismo, 69\% destes faziam referências e mantinham uma predominância, nos assuntos de jardinagem.

Dentre os serviços apresentados, o que recebe destaque é a reforma de jardins, oferecido por todas as empresas, evidenciando que este seja um dos mais efetivos trabalhos neste mercado. Esta realidade vem a sugerir a insatisfação dos clientes, o que talvez possa ser justificado pelo oferecimento e implantação de projetos mal configurados e fadados à condenação.

Muitas empresas também realizam a comercialização de espécies vegetais, associando os serviços de paisagismo às floriculturas e viveiros de mudas, como demonstrado pela venda de plantas ornamentais, mudas arbóreas e flores de corte, que representou $64 \%$ para as duas primeiras e $42 \%$ das empresas, para a última.

A elaboração de projetos paisagísticos encontra-se em percentual inferior àqueles mais oferecidos, diretamente voltados a jardins; porém, prevalece quanto à comercialização de espécies vegetais. Neste contexto ressalta-se a observação de Dourado (1997) quando identificou que, a partir dos anos 70, alguns paisagistas passaram a dedicar-se, apenas, à 
concepção de projetos, e não mais a todas as etapas de implantação e manutenção das paisagens. Em seu trabalho, o autor concluiu que a execução e manutenção de projetos paisagísticos foi uma forma eficiente e comum de inserção do profissional no mercado de trabalho, em especial daqueles em cuja base técnica predominam os conteúdos agrícolas.

\section{Qual é a formação do(s) profissional(is) que oferece(m) esses serviços?}

Esta questão possibilitou a identificação de 60 profissionais atuantes como paisagistas, sendo os mesmos originários de diferentes formações (Tabela 5).

TABELA 5 - Formação dos profissionais atuantes nas empresas amostradas.

TABLE 5 - Training of professionals working in the companies sampled.

\begin{tabular}{|c|c|c|}
\hline Formação dos profissionais identificados & $\begin{array}{c}\text { Frequência } \\
\left(\mathrm{N}^{\circ} \text { de profissionais) }\right.\end{array}$ & Percentual (\%) \\
\hline Arquitetura & 15 & 25,00 \\
\hline Cursos livres de paisagismo & 15 & 25,00 \\
\hline Engenharia Agronômica & 14 & 23,33 \\
\hline Técnico Agrícola & 5 & 8,33 \\
\hline Ensino Médio & 4 & 6,66 \\
\hline Técnico em Edificações & 3 & 5,00 \\
\hline Biologia & 2 & 3,33 \\
\hline Matemática & 1 & 1,66 \\
\hline Nenhum & 1 & 1,66 \\
\hline Total & 60 & 100 \\
\hline
\end{tabular}

A partir deste levantamento, constata-se heterogeneidade nas áreas de formação dos profissionais que atuam em paisagismo e, para análise dos dados apresentados, optouse por seguir a proposta de Zuin (2002), quanto à divisão desses profissionais em 3 grupos distintos. O primeiro grupo, composto por profissionais da paisagem legalmente habilitados, segundo a Resolução № 1.010/05 (CONFEA); num segundo grupo, aqueles que praticam paisagismo sem respaldo legal, mas receberam algum tipo de instrução relacionada, no qual baseiam a sua prática; o terceiro grupo, composto pela clientela dos cursos de paisagismo, os quais não conferem graus e não emitem diplomas. A este último grupo foram adicionados aqueles que decidiram mudar sua área profissional, e os demais atuantes que apresentam apenas formação escolar básica (Tabela 6). 
TABELA 6 - Distribuição dos profissionais entre os grupos descritos por Zuin (2002).

TABLE 6 - Distribution of professionals among the groups described by Zuin (2002).

\begin{tabular}{ccc}
\hline Grupos & Formação dos profissionais identificados & $\begin{array}{c}\text { Frequência } \\
\text { (Nº de profissionais) }\end{array}$ \\
\hline $1^{\circ}$ & Agronomia e Arquitetura & 29 \\
$2^{\circ}$ & Técnico Agrícola , Biologia e Técnico em Edificações & 10 \\
$3^{\circ}$ & Cursos livres de paisagismo, Ensino Médio, \\
Matemática e nenhum & 21 \\
\hline
\end{tabular}

Observa-se a representação de todos os grupos descritos por Zuin (2002), sendo, na Figura 6, dimensionada a participação de cada um deles, em função de seus percentuais.

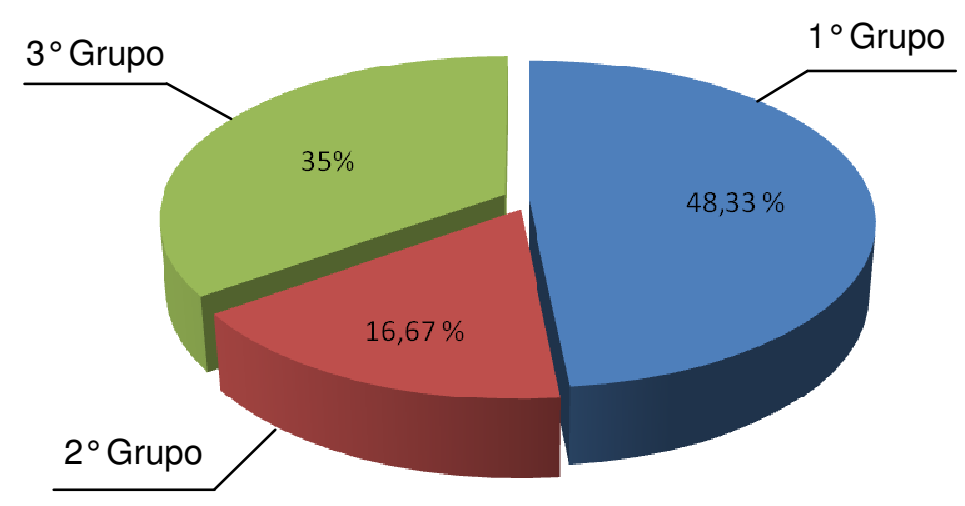

FIGURA 6 - Percentual dos grupos de profissionais identificados.

FIGURE 6 - Percentage of the professional groups identified.

Estes dados indicam que os diferentes grupos têm atuado neste mercado, demonstrando que o mesmo não tem apresentado regras e orientações quanto aos seus profissionais atuantes. Representando menos da metade dos profissionais no mercado (48,33\%) encontram-se aqueles com respaldo legal para a atividade profissional de paisagismo. Neste caso, os profissionais são diplomados em cursos superiores, habilitados e fiscalizados pelo conselho profissional (CONFEA/CREA).

O segundo grupo, com $16,67 \%$, apresenta profissionais, também formados em cursos superiores regulares, que seguem seus conselhos profissionais, porém não autorizados para exercerem a atividade profissional de paisagismo, o que não garante a realização de serviços com a fiscalização e registro dos mesmos.

Analisando a representação do 3 ำ grupo, que concentra $35 \%$ dos profissionais, notase que, mesmo não pertencendo a conselhos profissionais e sem órgão fiscalizador, atua de 
forma expressiva, não garantindo responsabilidade técnica sobre os trabalhos realizados.

Vale a pena ressaltar que os conselhos profissionais têm a missão de proteger a sociedade contra o risco a que estaria exposta pela execução de atividades técnicas por leigos ou, ainda, pelo mau exercício profissional, garantindo ao mesmo tempo, mercado de trabalho para os profissionais legalmente habilitados. Para a sociedade, essa atuação significa segurança nas obras e serviços prestados. (CREA-MG, 2005)

Sem o cumprimento da ética no oferecimento dos serviços de paisagismo, toda a sociedade sofre os seus prejuízos, o que é realmente preocupante, quando identifica-se que a maior parte dos profissionais atuantes neste mercado, 51,57\%, não está em condições favoráveis a este cumprimento, representados pelo $2^{\circ}$ e $3^{\circ}$ grupo analisado nesta pesquisa.

Para melhor compreender a aplicação da ética nos trabalhos oferecidos, segue-se Zuin (2005), quando descreve que a ética no paisagismo envolve três sub-temas básicos: 1. Ética ambiental, relativa ao grau de alteração dos habitats naturais e construídos, à introdução de contaminantes biológicos, à utilização indiscriminada de plantas, ao uso pouco criterioso de adubos, pesticidas, água e energia; 2. Ética profissional, relacionada com as práticas e processos do plano à execução, com o critério de seleção de plantas e de fornecedores, com o estabelecimento de preços dos serviços, com a responsabilidade técnica associativa e política; 3. Ética social, que resgata da posição de dispendiosa e supérflua ação cosmética uma profissão que é capaz de transformar e qualificar espaços.

\section{Qual é a situação do mercado de paisagismo para a empresa neste momento?}

As respostas desta questão são apresentadas na Tabela 7, e identificam que as empresas consideram como bom o mercado em que estão inseridas.

TABELA 7 - Visão quanto à situação do mercado de paisagismo nas empresas amostradas.

TABLE 7 - View regarding the landscaping market situation in the companies sampled.

\begin{tabular}{ccc}
\hline Situação do mercado & $\begin{array}{c}\text { Frequência } \\
\text { (N }{ }^{\circ} \text { de empresas) }\end{array}$ & Percentual (\%) \\
\hline Ótima & 5 & 10 \\
Boa & 24 & 48 \\
Regular & 18 & 36 \\
Ruim & 3 & 6 \\
Péssima & 0 & 0 \\
\hline Total & $\mathbf{5 0}$ & $\mathbf{1 0 0}$
\end{tabular}


Quando da relação dos dados da situação de mercado (Tabela 7) com os grupos profissionais atuantes em paisagismo, apresentados na Tabela 6, identificou-se que, dentre aqueles que consideraram o mercado em situação ótima, contam-se apenas os profissionais do $1^{\circ}$ e $2^{\circ}$ grupo. A realidade desta relação poderia ser justificada por uma atuação satisfatória desses profissionais no mercado de paisagismo, seja em função de suas qualidades técnicas de formação ou, ainda, pela condição de assumirem responsabilidade técnica sobre seus serviços.

A análise desta relação também evidenciou que, as respostas que relataram uma situação ruim de mercado envolveram apenas profissionais do $3^{\circ}$ grupo; ainda este grupo, também foi responsável por $50 \%$ das respostas que consideraram como em situação regular o mercado analisado. Os percentuais envolvendo os grupos de profissionais, em função das respostas obtidas por este questionamento, são apresentados na Figura 7.

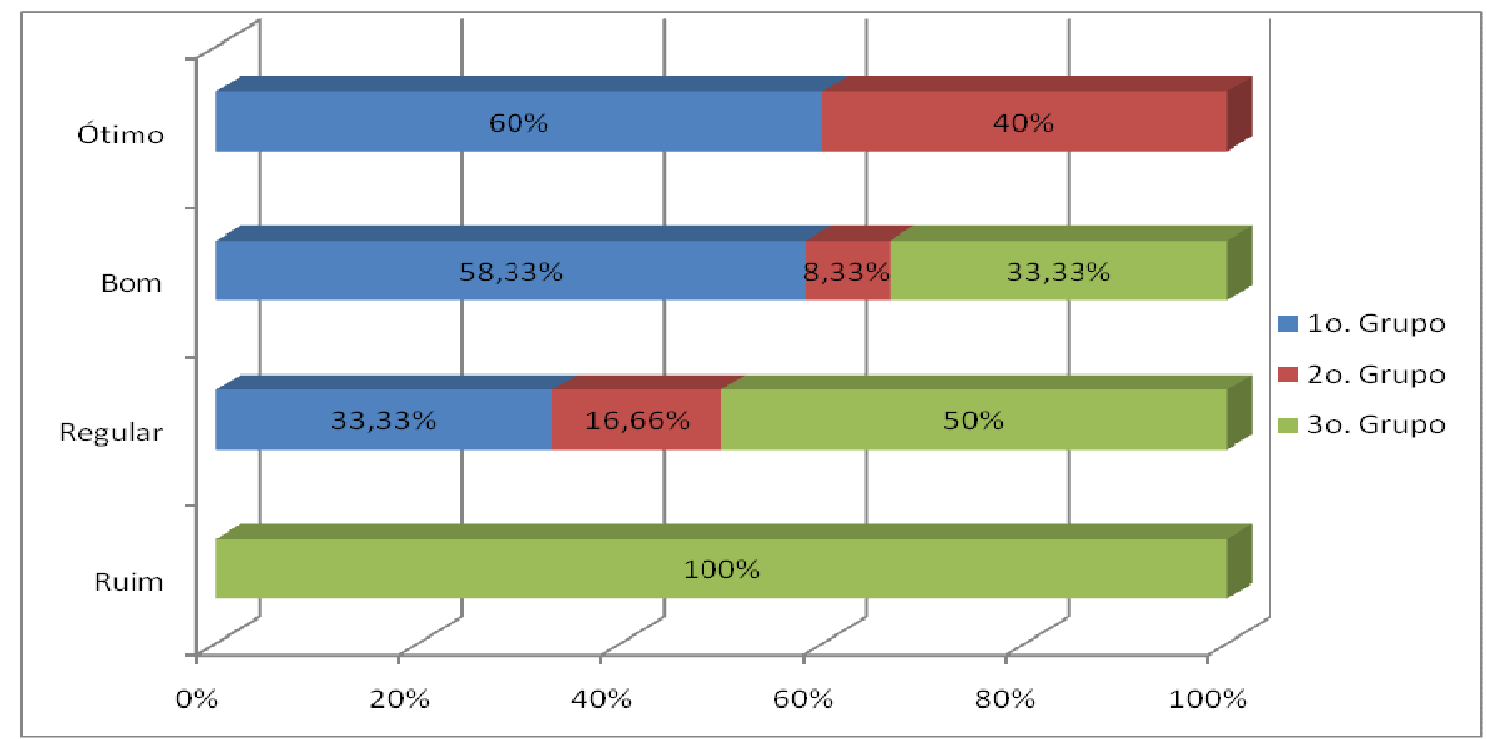

FIGURA 7 - Percentual de representação, dos grupos de profissionais, em cada uma das alternativas obtidas como resposta à questão 4.

FIGURE 7 - Representation percentage of professional groups in each of the alternatives obtained in response to question 4.

Nota-se que as empresas que atuam com profissionais do $1^{\circ}$ e $2^{\circ}$ grupos têm encontrado situação de mercado mais favorável do que aquelas cujos profissionais não apresentam formação em curso superior, ou vêm de uma mudança de rumo profissional. Esta análise pode sugerir uma tendência do mercado de paisagismo para a busca por 
profissionais melhor qualificados, e em condições favoráveis para a regulamentação de seus serviços prestados, garantindo a estes uma situação mais favorável de atuação.

\section{Acredita que os trabalhos com paisagismo são promissores no Estado?}

Os dados desta questão comprovam que os trabalhos com paisagismo têm sido promissores para seus investidores, os quais projetam uma abertura ainda maior de mercado neste setor de serviços, como demonstrado pelas respostas da Tabela 8.

TABELA 8 - Expectativa quanto ao mercado de paisagismo pelas empresas amostradas.

TABLE 8 - Expectations about the landscaping market by the companies sampled.

\begin{tabular}{ccc}
\hline Mercado promissor & $\begin{array}{c}\text { Frequência } \\
\text { (N' }{ }^{\circ} \text { de empresas) }\end{array}$ & Percentual (\%) \\
\hline Sim & 48 & 96 \\
Não & 02 & 04 \\
\hline Total & $\mathbf{5 0}$ & $\mathbf{1 0 0}$ \\
\hline
\end{tabular}

Os resultados apresentados constatam otimismo quanto ao desenvolvimento do paisagismo no Estado, uma visão que possibilita dimensionar aceitáveis ampliações deste mercado. Quanto aos comentários adicionais, 20 empresas manifestaram-se e, para melhor apresentá-los, os mesmos seguem relacionados e incorporados dentre aqueles citados com maior frequência.

- Valoração Imobiliária - a situação de crescimento deste mercado é consequência do valor que o paisagismo agrega aos imóveis no contexto urbano.

- Qualidade de vida - as pessoas estão buscando a qualidade de vida que o paisagismo pode proporcionar investindo em ambientes agradáveis.

- Prosperidade de condomínios - este mercado poderá crescer ainda mais em função da demanda de condomínios fechados.

- Reaproximação da natureza - as pessoas estão em busca de uma reaproximação com os elementos naturais.

- Melhor em outros Estados - em outros Estados brasileiros são ainda mais promissores.

- Poderia ser melhor - poderia ser melhor se tivesse profissionais bem formados. 
Os percentuais dos comentários obtidos seguem na Figura 8, e foram calculados com base no número total de empresas que se manifestaram.

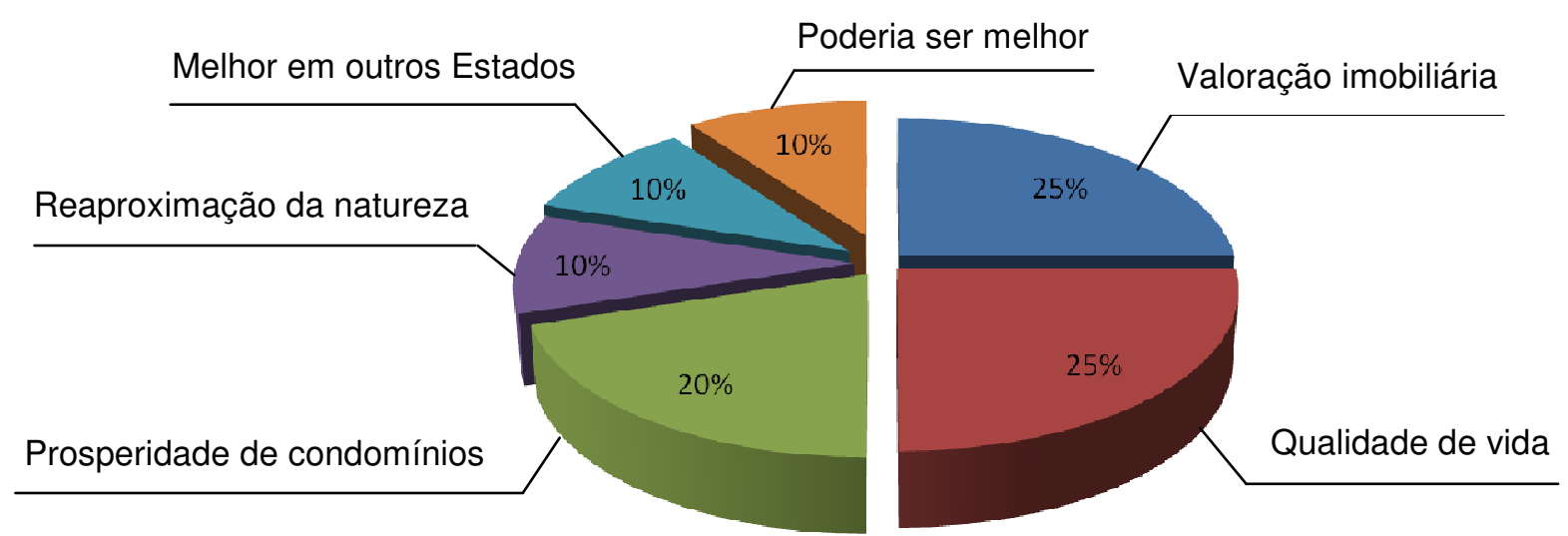

FIGURA 8 - Percentual de comentários adicionais relacionados a questão 05.

FIGURE 8 - Percentage of additional comments related to question 05.

Os comentários analisados com maior destaque para esta questão seguem alinhados com a visão apresentada por Phillips (2000) quando destaca que a paisagem tem um importante valor econômico agregado, por conta de sua qualidade e diversidade, e que, de fato, o papel da paisagem para o incremento de qualidade de vida urbana é extremamente importante para a sua população.

6. Acredita ser importante a participação de mais de um profissional na construção de paisagens? Quais deveriam ser os profissionais envolvidos?

As respostas desta questão evidenciam que as empresas acreditam em trabalhos multiprofissionais para o desenvolvimento do paisagismo (Tabela 9).

TABELA 9 - Importância da atuação de mais de um profissional na construção de paisagens.

TABLE 9 - Importance of more than one professional working in the construction of landscapes.

\begin{tabular}{ccc}
\hline Vários profissionais & $\begin{array}{c}\text { Frequência } \\
\text { (Nº empresas) }\end{array}$ & Percentual (\%) \\
\hline Sim & 41 & 82 \\
Não & 09 & 18 \\
\hline Total & $\mathbf{5 0}$ & $\mathbf{1 0 0}$ \\
\hline
\end{tabular}


Tal resultado corrobora com Zuin (2005) quando destaca que, se elencadas, as áreas de conhecimento necessárias ao exercício do paisagismo constituem uma listagem tão extensa, quanto multidisciplinar, indo do "A" da apreciação artística, e podendo chegar ao "Z" da zoobiologia. Assim, é virtualmente impossível que um único profissional domine todo o corpo de conhecimento relativo ao paisagismo.

Entretanto, quando os resultados apresentados são comparados com aqueles obtidos na questão 3, nota-se que, apesar de $82 \%$ das empresas acreditarem ser importante o envolvimento de mais de um profissional, na construção de paisagens, apenas $26 \%$ delas, efetivamente, utilizam desta estratégia para o oferecimento de seus serviços.

Admite-se que as empresas de paisagismo estão cientes da abrangência de áreas do conhecimento que os serviços oferecidos por elas englobam; porém, não atuam com diferentes profissionais para atender a todas elas. Esta situação pode ocorrer, seja em função do encarecimento dessa estrutura operacional ou, até mesmo, pela falta de profissionais que saibam trabalhar em equipe.

A segunda parte da questão identificou as origens acadêmicas dos profissionais que deveriam estar envolvidos em trabalhos de paisagismo, segundo as empresas do setor (Figura 9).

FIGURA 9 - Percentual de respostas quanto à necessidade, ou não, de profissionais cujas origens acadêmicas são mais frequentes dentre os paisagistas brasileiros.

FIGURE 9 - Percentage of answers on the necessity or not of professionals whose academic backgrounds are more frequent among the Brazilian landscape designers.

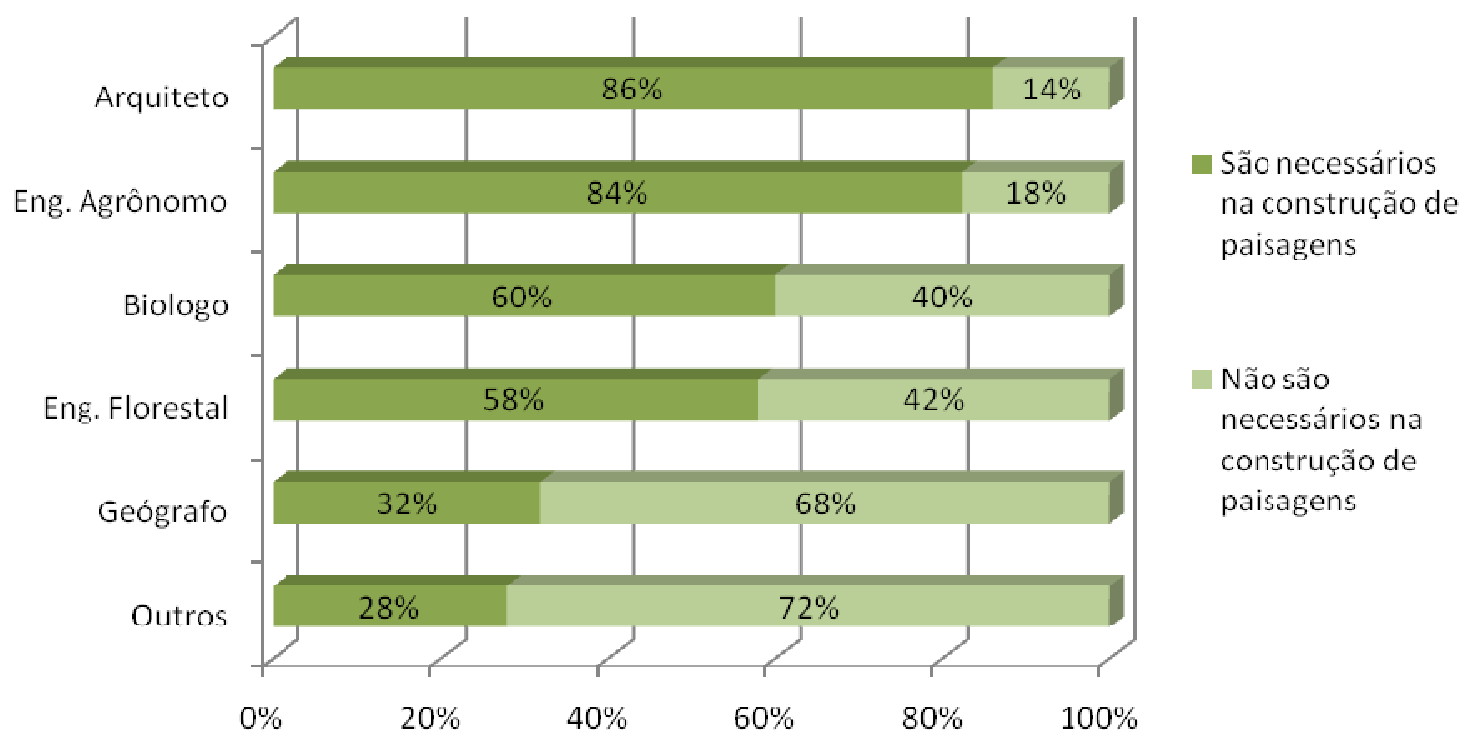


Observa-se destaque para a aceitação dos trabalhos desenvolvidos por arquitetos e agrônomos; entretanto, vale ressaltar que, dentre as empresas analisadas, apenas 10\% trabalham com esses dois profissionais, conjuntamente, no oferecimento de seus serviços.

Relativo aos comentários adicionais à esta questão, merece destaque a observação, quando da referência aos profissionais de engenharia florestal e geografia. O comentário que seguiu esta escolha, como sendo positiva, acrescentou que isso caberia quando em projetos de grande porte, em sua maioria em áreas rurais, e não urbanas $(70 \%$ dos respondentes).

\section{Sente que os recém-formados têm interesse por trabalhos de paisagismo?}

Os resultados desta questão são apresentados na Tabela 10.

TABELA 10 - Visão das empresas de paisagismo quanto ao interesse dos recém-formados por trabalhos de paisagismo.

TABLE 10 - View of landscaping companies regarding the interest of newly graduated students for jobs in landscaping.

\begin{tabular}{ccc}
\hline Recém-formados têm interesse & $\begin{array}{c}\text { Frequência } \\
\left(\mathbf{N}^{\circ} \text { de empresas) }\right.\end{array}$ & Percentual (\%) \\
\hline Sim & 18 & 36 \\
Não & 32 & 64 \\
\hline Total & $\mathbf{5 0}$ & $\mathbf{1 0 0}$ \\
\hline
\end{tabular}

A análise dos dados apresentados proporcionou a visão de que os recém-formados, em sua maioria, não têm buscado as empresas de paisagismo com interesse para atuação nesta atividade profissional. Buscar esta visão fundamenta-se na idéia de que, uma das formas de medir o interesse dos recém-formados por um campo de atuação profissional, pode ser em função de sua procura por contato com profissionais da área, seja para realização de estágios ou, até mesmo, para considerar oportunidades futuras de emprego.

A partir dos dados apresentados, entende-se que esta não tem sido uma estratégia utilizada pelos recém-formados, para inclusão em trabalhos com paisagismo; o que pode evidenciar duas situações: os recém-formados não sentem interesse por este campo de atuação, ou há um distanciamento entre as empresas de paisagismo e aqueles em formação nesta atividade. As informações que fundamentaram a segunda situação apresentada seguem nas observações feitas por 15 empresas que comentaram a questão.

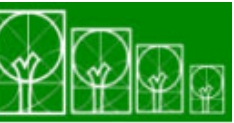

S $\cdot \mathbf{B} \cdot \mathbf{A} \cdot \mathbf{U}$ Soc. Bras. de Arborização Urbana

REVSBAU, Piracicaba - SP, v.5, n.4, p.57-80, 2010 
- Desconhecimento do mercado - os recém-formados não buscam trabalhos com paisagismo em consequência da falta de informação adequada sobre a área.

- Procura por estágio - o contato que os recém-formados estabelecem com as empresas, para o desenvolvimento de estágios, é pequeno.

- Profissionais mais interessados - dentre os recém-formados, os dos cursos de arquitetura e engenharia agronomia são os que mais procuram a empresa.

Para analise dos comentários, segue a Figura 10, que apresenta seus percentuais.

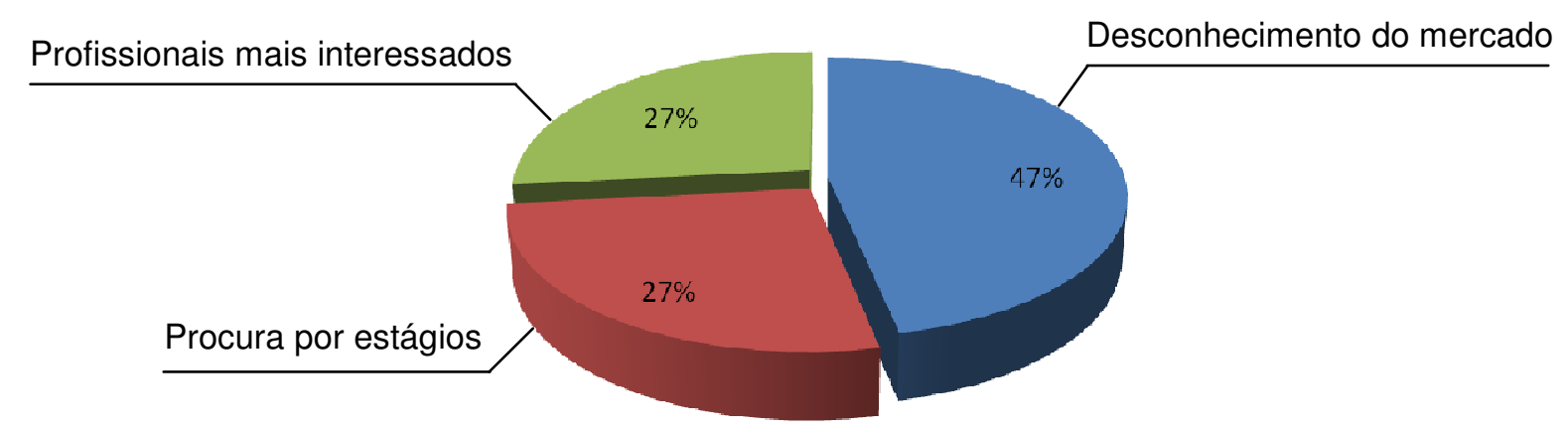

FIGURA 10 - Percentual de comentários adicionais relacionados à questão 07.

FIGURE 10 - Percentage of additional comments related to question 07.

Nota-se que $47 \%$ das empresas, que comentaram esta questão, identificam que os recém-formados desconhecem o mercado de paisagismo, e por isso acabam não tendo interesse por este campo profissional; este fato também é evidenciado quando, na pesquisa realizada pelo CONFEA (2008), destaca-se o comentário das empresas com a preocupação na contratação de recém-formados, uma vez que os mesmos não têm conhecimento do mercado quando seguem para atuação profissional.

8. Sente que os recém-formados foram devidamente capacitados pelas instituições de ensino superior, para o oferecimento de serviços relacionados ao paisagismo?

Os resultados desta questão seguem na Tabela 11, e evidenciam o despreparo dos recém-formados para atuação em paisagismo, segundo as empresas do setor. 
TABELA 11 - Visão que as empresas de paisagismo apresentam quanto à capacitação dos recém-formados para atuação em paisagismo.

TABLE 11 - View that landscaping companies have on the training of newly graduated students to work in landscaping.

\begin{tabular}{ccc}
\hline Recém-formados foram capacitados & $\begin{array}{c}\text { Frequência } \\
\text { (N' }{ }^{\circ} \text { de empresas) }\end{array}$ & Percentual (\%) \\
\hline Sim & 6 & 12 \\
Não & 44 & 88 \\
\hline Total & $\mathbf{5 0}$ & $\mathbf{1 0 0}$ \\
\hline
\end{tabular}

A situação de despreparo dos recém-formados, no atendimento ao mercado de paisagismo, é uma realidade importante para ser analisada, uma vez que seus empreendedores projetam expansão da atividade (questão 5), o que demandará bons profissionais para atuação. De acordo com Gondim (2002), a organização universitária, como qualquer outra esfera da educação formal, está sendo convocada a assumir um duplo papel: o de educar - que se distingue da mera instrução - e o de preparar profissionais para atender às novas demandas do mercado de trabalho.

Comentários adicionais foram dados em 25 entrevistas, como organizado a seguir.

- Falta de prática - os recém-formados não sabem apor os conhecimentos aprendidos de forma prática no paisagismo.

- Capacitação mais específica - as áreas de agronomia e arquitetura são aquelas que melhor preparam seus profissionais para atuação neste mercado.

Os percentuais obtidos, quanto aos comentários, seguem na Figura 11.

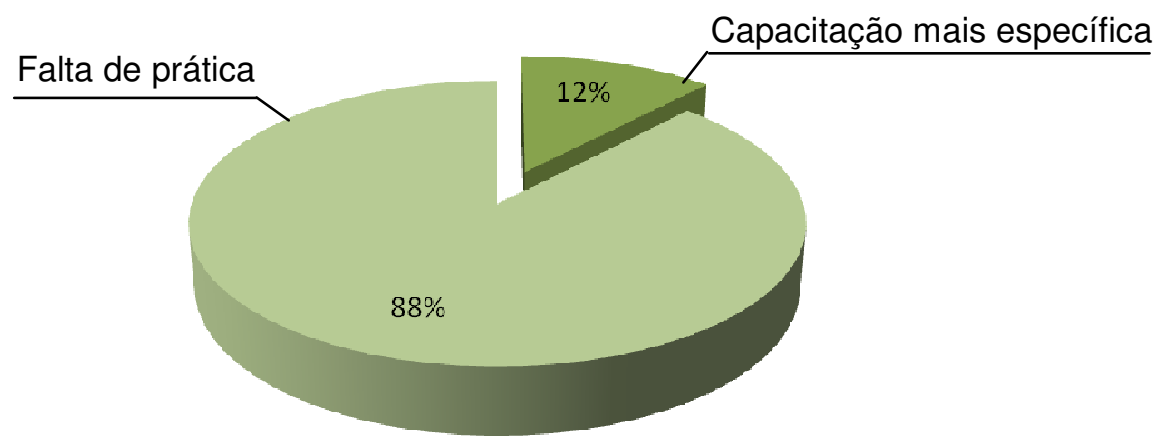

FIGURA 11 - Percentual de comentários adicionais relacionados à questão 08.

FIGURE 11 - Percentage of additional comments related to question 08.

A análise dos comentários demonstra que as empresas observam uma realidade de

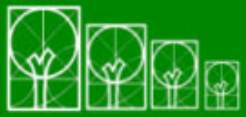

S $\cdot \mathbf{B} \cdot \mathbf{A} \cdot \mathbf{U}$ Soc. Bras. de Arborização Urbana

REVSBAU, Piracicaba - SP, v.5, n.4, p.57-80, 2010 
capacitação ineficaz, provavelmente advinda do distanciamento entre as instituições de ensino e as necessidades do mercado a ser atendido; tal fato também foi destacado pelo CONFEA (2008), quando revelou que aquilo que as escolas ensinavam deixa muito a desejar com o atendimento das demandas do mercado de trabalho, ressaltando como principal queixa a falta da prática profissional.

\section{CONCLUSÃO}

No mercado de paisagismo, puderam ser encontradas empresas do setor, em três situações distintas, quanto ao tempo de permanência no mercado: aquelas que estão iniciando investimentos neste ramo; outras, já estabelecidas no mercado, que projetam investimentos futuros; e, ainda, as de tempo intermediário no oferecimento desse serviço. Em geral, esse mercado apresentou um tempo médio de atuação de 13,27 anos.

Os serviços oferecidos como paisagismo, apresentaram-se diretamente relacionados a jardins e utilização de plantas ornamentais, recebendo maior destaque aquele que trata de reforma de jardins, apresentado por todas as empresas analisadas.

A realidade da associação, entre os serviços prestados com jardinagem e plantas ornamentais, possibilita a observação de que este mercado tem uma forte ligação com as ciências agrárias; porém, apesar desta ligação, constatou-se heterogeneidade quanto às áreas de formação dos profissionais envolvidos nos trabalhos de paisagismo. Dentre os profissionais encontrados, menos da metade $(48,33 \%)$ apresentaram respaldo legal para a atividade de paisagismo, sendo representados pelos arquitetos e engenheiros agrônomos. Destaca-se que $51,57 \%$ dos profissionais não estavam em condições favoráveis ao cumprimento de seus trabalhos com a ética e as responsabilidades técnicas necessárias a esta atividade.

A despeito desta realidade, as prestadoras de serviço consideraram como bom o mercado em que estão inseridas, e projetaram prosperidade, deste setor. Quanto ao desenvolvimento do paisagismo, em equipes multiprofissionais, as empresas mostraram-se favoráveis a esta realização; porém, apenas $26 \%$ delas, efetivamente, utilizavam esta estratégia para o oferecimento de seus serviços. Destaca-se, ainda, que $64 \%$ delas observam que os recém-formados não as têm buscado, com interesse para atuação nesta atividade profissional. Por outro lado, evidenciou-se o despreparo dos recém-formados para atuação em paisagismo, pelas empresas de paisagismo.

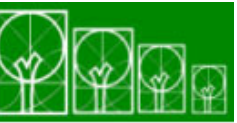

$\mathbf{S} \cdot \mathbf{B} \cdot \mathbf{A} \cdot \mathbf{U}$ Soc. Bras. de Arborização Urbana

REVSBAU, Piracicaba - SP, v.5, n.4, p.57-80, 2010 


\section{AGRADECIMENTOS}

Os autores agradecem ao Prof. Dr. Hilton Thadeu Zarate do Couto e a Dra. Giuliana Del Nero Velasco, pela colaboração e encorajamento a esta pesquisa, e são também gratos ao Conselho Nacional de Desenvolvimento Científico e Tecnológico (CNPq).

\section{REFERÊNCIAS BIBLIOGRÁFICAS}

ARENDT, H. A Condição humana. 10 ed. Rio de Janeiro: Forense Universitária, 2005. $352 \mathrm{p}$.

BARBOSA, A.C.S. Paisagismo, jardinagem \& plantas ornamentais. 6.ed.. São Paulo: Iglu, 1989. $232 \mathrm{p}$.

BRASIL. Conselho Federal de Engenharia, Arquitetura e Agronomia. Resolução № 1.010, de 22 de agosto de 2005. Brasília: Publicada no Diário Oficial da União de 4 de setembro de 2006 - Seção 1 Pág. 116 a 118.

CÉSAR, L.P.M. Visões de mundo e modelos de paisagismo. 2003. 270 p. Tese

(Doutorado em Desenvolvimento Sustentável) - Universidade de Brasília, Brasília, 2003.

CONFEA, Conselho Federal de Engenharia, Arquitetura e Agronomia. Mercado de trabalho para o Engenheiro e Tecnólogo no Brasil. Sumário Analítico. CONFEA/CNI. Brasília-DF, 2008. doc., 45p. Disponível em: <http://www.crea-

sc.org.br/webcrea/webcrea2008/imagens/RelatoriodaPesquisaRevisado2008.pdf>

CREA-MG. Cartilha do estudante: sonhar, aprender, construir. Belo Horizonte, 2005. 27p. Disponível em: <http://www.crea-mg.org.br/imgs/cart estudante.pdf>

DOURADO, G.M. Paisagismo no Brasil: itinerário de uma profissão. In: DOURADO, G.M. Visões de Paisagem - Um panorama do paisagismo contemporâneo no Brasil. São Paulo: ABAP. 1997. p.8-16.

DRUMOND, A.A.L., Avaliação do perfil dos jardineiros e suas técnicas de jardinagem empregadas no paisagismo na cidade de Viçosa 2005. 114 p.Tese (Obtenção do título de Magister Scientiae) - Universidade Federal de Viçosa, Viçosa, 2005.

GASPARIN, M.. Sercomtel vende empresa de call center para sanear contas. Gazeta do Povo, Curitiba, 4 fev. 2006. p. 19.

GONÇALVES, W. Paisagem: objeto de trabalho do arquiteto paisagista. In:

Paisagem e ambiente - Ensaios IV. São Paulo: FAUUSP, 1992. 10p.

GONDIM, S.M.G. Perfil profissional e mercado de trabalho: relação com formação acadêmica pela perspectiva de estudantes universitários. Estudos de Psicologia., Natal, v.7, n.2, p. 299-309, 2002. Disponível em: <http://www.scielo.br/pdf/epsic/v7n2/a11v07n2.pdf> 
GÜNTHER, H. Como elaborar um questionário. Série: Planejamento de Pesquisa nas Ciências Sociais, $n^{\circ}$ 01. Brasília, Laboratório de Psicologia Ambiental- UnB, 2003. Disponível em:<http://web.dv.utfpr.edu.br/www.dv/professores/arquivos/Thomas\%20Newton\%20Mart in/MSc PPGDR questionario 04.pdf> Acesso em: 08 jan. 2010.

HARVEY, D. Spaces of capital: Towards a critical geography. New York: Routledge, 2001. $448 \mathrm{p}$.

IGC. Mapa das Regiões Administrativas e Metropolitanas do Estado de São Paulo. Disponível em: <http://www.igc.sp.gov.br/copimapas.htm\#regias> Acesso em: $18 \mathrm{dez}$. 2009.

MEDEIROS, J.M.M. Visões de um paisagismo ecológico na orla do lago Paranoá. 2008. 200 p. Dissertação (Mestre em Arquitetura e Urbanismo) - Universidade de Brasília, Brasília, 2008.

PETTAN, J.C.; GONÇALVES, V.A. Exposições, debates e proposições - Market. In GRUPO DE ENGENHEIROS AGRÔNOMOS PAISAGISTAS DO ESTADO DE SÃO PAULO. 1998, São Paulo. Anais... São Paulo: GEAPESP/AEASP. 1998. p. 113-119.

PHILLIPS, A. IUCN Commission on environmental Law. Landscape conservation Law: present tremds and perspectives in International and comparative Law. Gland, Switzerland and Cambridge, UK. 2000. p. 17-25.

SEADE. PIB dos Municípios Paulistas. Relatório de Divulgação. São Paulo. Dez, 2008. Disponível em: $<$ http://www.seade.gov.br/produtos/pibmun/pdfs/PIBMunicipal 2006.pdf>Acesso em: 08 jan. 2010.

SPIRN, A.W. O Jardim de granito: a natureza no desenho da cidade. São Paulo: Edusp, 1995. $360 \mathrm{p}$.

VIEIRA, M.E.M. O jardim e a paisagem: espaço, arte, lugar. São Paulo: Annablume, 2007. $254 \mathrm{p}$.

WENDEL, H. A cidade e a natureza: a apropriação, a valorização e a Sofisticação da natureza nos empreendimentos imobiliários de alto padrão em São Paulo. GEOUSP Espaço e Tempo, São Paulo, n.20, p. 65 - 77, 2006.

ZUIN, A.H.L. A conjoint study towards transformative landscape architectural education in Brazil. 2002. 323 p. Tese (Doutorado em Filosofia) - Edinburgh College of Art/ Heriot-Watt University, Edinburgh, 2002.

ZUIN, A.H.L. Ética e paisagismo - contribuição ao debate. In: CBCEARA:45 CBOlericultura/ 15 CBFloricultura e Plantas Ornamentais/2 CB CTecidos de Plantas, 2005, Fortaleza CE. Horticultura Brasileira. Brasília, v. 23. p. 554-554, 2005. 